Especial: Profesores de Estudios Generales Investigan

II Sección: Docentes e investigación: tarea continua en Estudios Generales

\title{
Apuntes para una Historia del Consejo Nacional de Producción
}

\author{
Emmanuel Mora Iglesias \\ Universidad de Costa Rica, Costa Rica \\ emorai1@yahoo.no \\ https://orcid.org/0000-0002-9880-1265
}

Recibido: 20 de diciembre de 2019

Aceptado: 5 de febrero de 2020

Resumen: Este articulo sintetiza información sobre la fundación y los inicios del Consejo Nacional de Producción de Costa Rica durante la década de 1940 y 1950 con información actualizada tomada no solamente de bibliografía actualizada sobre el tema sino también de los mismos archivos de esta institución que fue uno de los motores de la producción nacional durante estos años. Se publican algunas fotos inéditas.

Palabras clave: Historia económica; Consejo Nacional de Producción; Historia de las Instituciones; Primera República de Costa Rica; Segunda República de Costa Rica; Producción Agrícola.

\section{Notes for a History the Consejo Nacional de Producción}

Abstract: This article synthetizes information about the foundation and the beginnings of the Consejo Nacional de Producción of Costa Rica during the

\section{(c) (i) (2) (2)}

La Revista Estudios es editada por la Universidad de Costa Rica y se distribuye bajo una Licencia Creative Commons Atribución-NoComercial-CompartirIgual 3.0 Costa Rica. Para más información envíe un mensaje a 


\section{Especial: Profesores de Estudios Generales Investigan}

decades of 1940 and 1950 not only using actualised bibliography on the subject but as well the archives of this institution which was at the very centre of national production during this years.

Keywords: Economic History; Consejo Nacional de Producción; History of Institutions; First Republic of Costa Rica; Second Republic of Costa Rica; Agricultural Production.

Las semillas del Consejo Nacional de Producción se siembran durante del gobierno de don Teodoro Picado en el año de 1944 por medio de una ley emitida por el Congreso. Es sin embargo este primer Consejo no es un organismo con personalidad jurídica propia sino una Comisión integrada por altos funcionarios del Gobierno y el presidente de la junta directiva del Banco Nacional de Costa Rica. ${ }^{i}$

Debemos recordar que este Banco era el heredero directo del vetusto Banco Internacional de Costa Rica, estatizado por el gobierno de González Flores y que tenía a su cargo en parte las funciones directoras de la economía estatal que habría de ejercer el Banco Central de Costa Rica creado en 1950. El artículo sexto de la Ley N.110 que creó el Consejo dice textualmente:

...los términos y condiciones de los contratos de compra que otorgará el Banco a los productores de que habla el contrato anterior serán fijados de común acuerdo por los Secretarios de Estado en los Despachos de Agricultura y de Trabajo y el presidente de la junta directiva del Banco Nacional de Costa Rica. Esta comisión constituirá el Consejo Nacional de Producción (CNP), y sus miembros propietarios podrán ser sustituidos en ausencias temporales por los respectivos Subsecretarios de Estado $u$ Oficiales Mayores, y de parte del Banco Nacional de Costa Rica, por el vicepresidente de la junta directiva. (La Gaceta. Ley 110.28 de Julio de 1944, p.1372).

\section{(๑) $\odot \Theta \odot$}

La Revista Estudios es editada por la Universidad de Costa Rica y se distribuye bajo una Licencia Creative Commons Atribución-NoComercial-CompartirIgual 3.0 Costa Rica. Para más información envíe un mensaje a 
Especial: Profesores de Estudios Generales Investigan

Si seguimos los contenidos de la ley nos daremos cuenta que muchos de los lineamientos que habría de seguir el CNP a través de los años aparecen ya dibujados en las funciones que asume el Banco Nacional de Costa Rica, cuyo presidente es un miembro de este primer Consejo. Así en el susodicho artículo nos habla sobre la fijación de precios,

... los precios de los productos serán fijados con base en las estadísticas de costo que llevará el Banco, más una ganancia racional para el productor. Los precios de venta serán fijados por el mismo procedimiento. (La Gaceta. Ley 110.28 de Julio de 1944, p.1372).

El artículo siguiente, el cuarto, es aún más explicito;

...el Banco Nacional con la aprobación de la Secretaría de Agricultura y por cuenta del fondo creado por esta Ley, podrá comprar también a otros agricultores nacionales sus productos, cuando fuere necesario para mantener los precios que se considere justo que obtenga el productor. Del mismo modo, deberá proceder a la venta de dichos productos cuando fuere necesario para sostener o bajar los precios del mercado. (La Gaceta. Ley 110.28 de Julio de 1944, p.1372).

El fomento de la producción aparece como su atribución en el primer artículo de esta Ley;

...crease un fondo de 2.000 .000 el cual se denominará Fondo para la Investigación de la Producción del Maíz, Arroz, Frijoles, Papas y demás artículos agrículas básicos del consume popular, destinado a formar el capital de trabajo e inversión de la Sección Fomento de la Producción creada por la ley N.26 del 6 de Noviembre de 1943, anexa al Banco Nacional de Costa Rica. (La Gaceta. Ley 110.28 de Julio de 1944, p.1372).

\section{(C) $(\Theta \odot$}

La Revista Estudios es editada por la Universidad de Costa Rica y se distribuye bajo una Licencia Creative Commons Atribución-NoComercial-CompartirIgual 3.0 Costa Rica. Para más información envíe un mensaje a 
Especial: Profesores de Estudios Generales Investigan

Se desprende de esta Ley, y de la siguiente, el papel financiero;

...autorízase al Banco Nacional de Costa Rica para prestar de sus fondos propios y en la cuantía que exija la demanda, por medio sus Juntas Rurales de Crédito, a los núcleos de pequeños agricultores que se organicen por medio de la Sección de Fomento de la Producción, hasta el 100\% del valor calculado del costo de cultivo y recolección del créditos llegaren a producir, mientras no esté organizado el seguro producto objeto del crédito prendario. Las pérdidas que esta clase de contra pérdidas en las cosechas, serán absorbidas por la Sección de Fomento de la Producción. (La Gaceta. Ley 110.28 de Julio de 1944, p.1372).

El control de las importaciones y exportaciones de productos agrícolas está a cargo de la Secretaría de Agricultura, participante también de la Comisión del Consejo con asesoramiento del Banco Nacional de Costa Rica de acuerdo al artículo quinto de la Ley,

...a partir de la presente ley, el control y fiscalización de todas las importaciones y exportaciones de artículos o productos agrícolas quedará a cargo de la Secretaría de Agricultura, quien deberá proceder en la resolución de las mismas oyendo el parecer de los departamentos técnicos del Banco Nacional. (La Gaceta. Ley 110.28 de Julio de 1944, p.1372).

El artículo sexto de la Ley es muy interesante ya que autoriza al Banco Nacional a "importar o comprar semillas, almácigos, abonos, maquinarias y útiles de labanza, para venderlos directamente a los agricultores a precio de costo y con las facilidades que estime convenientes." (La Gaceta. Ley 110.28 de Julio de 1944, p.1372).

Autoriza esta misma ley el arendamiento de maquinarias de un costo elevado a los productores del país así como queda el Banco Nacional de Costa Rica con autorización para "construir o arrendar bodegas en los lugares donde fuere necesario, los cuales se destinarán a los fines de esta ley y serán administradas por el Banco." (La Gaceta. Ley 110.28 de Julio de 1944, p.1372).

\section{(c) (i) (-)}

La Revista Estudios es editada por la Universidad de Costa Rica y se distribuye bajo una Licencia Creative Commons Atribución-NoComercial-CompartirIgual 3.0 Costa Rica. Para más información envíe un mensaje a 


\section{Especial: Profesores de Estudios Generales Investigan}

En definitiva, vemos ya en esta ley estipuladas las funciones de almacenaje, fijación de precios, financiamiento, fomento de la producción, control de importaciones y exportaciones de productos agrícolas, importación de bienes de y para la agricultura y arrendamiento de maquinaria a los productores; todas ellas repartidas entre miembros de la Comisión llamada Consejo Nacional de Producción.

Los antecedentes más cercanos a esta ley datan desde la creación misma del Banco Nacional de Costa Rica, en 1917, en plena Primera Guerra Mundial. Con la creación de esta primera entidad bancaria de carácter público en el país se vinieron a crear también las famosas Juntas Rurales de Crédito que como su nombre lo indica daba crédito y demás asesoramiento técnico a los campesinos, algo que nunca antes se había dado en el país. Posteriormente en 1940 se estableció la Estadística de Producción, dependiente de la Secretaría de Estado en los despachos de Fomento y Agricultura. Asì obligaba a los productores o dueños de los fondos empleados en la producción a declarar "el área, clase y demás pormenores de las siembras o cultivos existentes o que se propongan realizar." (La Gaceta. Ley N.7728 de Junio de 1940, p.1285). La desobedencia a esta ley acarreaba una sanción en forma de multa de 100 a 200 colones de la época o trabajo personal por ese valor en obras nacionales o municipales. Es de subrayar que con esto se podía determinar en forma más precisa proyecciones sobre la producción nacional lo que facilitaría un potencial control de precios.

En efecto, tan sólo tres años luego de la promulgación de esta ley nos encontramos con la número 26 decretada el 26 de Octubre. Se crea por medio de esta Ley un fondo de un millón y medio de colones "con el objeto de dar debida protección y estímulo a la producción nacional de los artículos agrícolas básicos de consumo popular: maíz, frijoles y papas, y amparar los intereses legítimos del consumidor." (La Gaceta. Ley N.7728 de Junio de 1940, p.1285).

\section{(c) (i) (-)}

La Revista Estudios es editada por la Universidad de Costa Rica y se distribuye bajo una Licencia Creative Commons Atribución-NoComercial-CompartirIgual 3.0 Costa Rica. Para más información envíe un mensaje a revistaestudios.eeg@ucr.ac.cr. 


\section{Especial: Profesores de Estudios Generales Investigan}

Este fondo provenía de un contrato que haría el Poder Ejecutivo, por medio de las Secretarias de Hacienda, Agricultura y Trabajo, con el Banco Nacional de Costa Rica. Veáse que ya en esta ley se mencionan los miembros que integrarían el Consejo Nacional de Producción. El fondo se llamaría precisamente Fondo para la compra de Arroz, Frijoles, Maíz y Papas. La mayor parte de éste sería formado por dinero proveniente de bonos para la defensa, ya volveremos sobre este particular.

El Banco Nacional de Costa Rica es desde este momento el autorizado "para entregar prestámos para la financiación de las compras" (La Gaceta. Ley N.7728 de Junio de 1940, p.1285), (Art.4), para hacer contratos con los productores de los productos mencionados "comprometiéndose a comprarles al contado sus cosechas" (La Gaceta. Ley N.7728 de Junio de 1940, p.1285), (Art.5) en los mismos centros de producción "por medio de los Organismos responsables que determine el Banco Nacional, con este propósito en los lugares que fuere necesario, el Poder Ejecutivo construirá bodegas que serán administradas por el Banco" (La Gaceta. Ley N.7728 de Junio de 1940, p.1285). Así mismo los artículos 11 y 12 nos hablan que el Poder Ejecutivo (a través de la Secretaría de Agricultura) "prestará toda la ayuda necesaria a fin de incrementar la producción mediante la racionalización de la agricultura" y que la Secretaría de Trabajo y Previsión Social será la encargada de organizar un plan general

...de distribución de los artículos agrícolas de que habla la presente de tal suerte que éstos lleguen a manos del consumidor, a precio conveniente, más una utilidad moderada para los distribuidores necesarios para ponerlos directamente en manos del público (La Gaceta. Ley N.7728 de Junio de 1940, p.1285).

He aquí, en esta ley, los más lejanos antecedentes de los que tenemos noticia, sobre diversas funciones con la que habría de contar en última instancia el CNP e incluso sobre la creación de los estancos.

\section{(C) $(\Theta \Theta \odot$}

La Revista Estudios es editada por la Universidad de Costa Rica y se distribuye bajo una Licencia Creative Commons Atribución-NoComercial-CompartirIgual 3.0 Costa Rica. Para más información envíe un mensaje a 
La razón de estas leyes y de la posterior creación del Consejo Nacional de Crédito y Producción durante la Primera República. La coyuntura de la Segunda Guerra Mundial.

Para entender la promulgación de todas estas medidas, sin sentido aparente, debemos remontarnos al contexto histórico de la primera mitad del siglo $\mathrm{XX}$.

Recordemos que comenzando el siglo pasado la doctrina económica y política que imperaba en el mundo Occidental era el liberalismo defensor del laissez-faire, laissez passer, en el sentido que entre otras cosas, la autoridad gubernamental no debía intervenir en aspectos de orden económico. Los precios debían regirse única y exclusivamente por las leyes de oferta y demanda.

Los sistemas económicos liberales tendrían su primer prueba de fuego tras el estallido de la Primer Guerra Mundial (1914), en donde muchos gobiernos intervienen en sus economías ante la crisis económica que la guerra provocó. En todo este proceso Costa Rica no fue la excepción y el gobierno de González Flores, como anteriormente mencionamos, estatiza el Banco Internacional de Costa Rica y propone la creación del impuesto territorial lo que precisamente acarrea su caída por parte de grupos de interés contrarios a esta medida. Durante esta administración se habían creado las Juntas Rurales de las que ya habíamos hablado.

La crisis de 1929 fue el segundo gran escollo del liberalismo. Aunque las causas de la misma no están del todo claras lo que si sabemos con certeza son sus efectos depresivos en la economía. El gobierno de los EE.UU. pudo salir de ella únicamente por medio de su intervención directa en la dirección de la economía y su efecto que se materializó con la creación de puestos de trabajo.

\section{(c) (i) (2) (2)}

La Revista Estudios es editada por la Universidad de Costa Rica y se distribuye bajo una Licencia Creative Commons Atribución-NoComercial-CompartirIgual 3.0 Costa Rica. Para más información envíe un mensaje a 


\section{Especial: Profesores de Estudios Generales Investigan}

Nos ubicamos ahora en el año de 1941. Tras el ataque japonés a Pearl Harbor Costa Rica le declaró la guerra al Imperio de Japón el día 8 de diciembre y al Reino de Italia como al Reich alemán el 11 de Diciembre, entrando así en un conflicto de carácter mundial cuyos efectos económicos ya se habían comenzado a sentir en nuestro medio (Obregón, 198, pp.309 y ss.). No obstante el costo de la vida sube en forma alarmante durante el período de 1942 a 1945 siendo los sectores más pobres los más afectados. (Gamboa, 1985, p.36).

Al declararse la guerra el gobierno crea la Junta de Defensa Económica, integrada por los secretarios de Estado en los despachos de Hacienda y Agricultura, el gerente del Banco Nacional y otros miembros nombrados por el Congreso. Obsérvese que precisamente la Estadística de Producción, creada por la Ley N.77 es dependiente de la Secretaría de Estado en los Despachos de Fomento y Agricultura y que de acuerdo a la Ley 26 de 1943 son estas Secretarías las que deben hacer un contrato con el Banco Nacional para dar protección y estímulo a la producción nacional base de la Ley 110 de 1944 que estableció el Fondo para la Intensificación de la Producción. No es coincidencia entonces que "el campo de acción de la Junta se relaciona con el fomento y protección de la agricultura, industria y comercio del país dentro del panorama derivado del conflicto armado." (Gamboa, 1985, p.58).

El 12 de Diciembre de 1941 se da la emisión de bonos de defensa nacional. El producto de estos bonos podía ser invertido en la defensa nacional o en "la financiación del plan de incremento agrícola, cuyo presupuesto será presentado por la secretaría de Agricultura a la Secretaría de Hacienda." La Gaceta, ley N.26 13 de Diciembre de 1942, p.2111).

Efectivamente la producción agrícola se encontraba en crisis, una crisis que hundía sus raíces en la década de los 30, agudizada durante el gobierno de don León Cortés Castro (1936-1940).

\section{(ब) $(\Theta \odot$}

La Revista Estudios es editada por la Universidad de Costa Rica y se distribuye bajo una Licencia Creative Commons Atribución-NoComercial-CompartirIgual 3.0 Costa Rica. Para más información envíe un mensaje a 


\section{Especial: Profesores de Estudios Generales Investigan}

La crisis tiene varios orígenes como el asunto de la tenencia de la tierra, falta de apoyo técnico, maquinaria, asistencia a los campesinos en la comercialización, créditos y movimiento cooperativo, altibajos en los precios de venta en el exterior y el vacío que representa la no existencia de la secretaría en el ramo. ${ }^{\text {ii }}$

Es por la Segunda Guerra Mundial que el problema se agudiza. En primer lugar el principal mercado para la exportación de café, Alemania, había desaparecido al ser este enemigo de guerra. La producción de arroz, maíz, frijoles (Gamboa 1982, p.76) y caña de azúcar disminuye ante la de caucho y otros productos que eran materias primas para artículos extensivamente usados en el conflicto."ii La disponibilidad de mano de obra sufre un serio revés cuando muchos trabajadores emigran temporalmente a Panamá para trabajar en obras de ampliación del Canal debidas también a la guerra. La política crediticia de los bancos para con respecto a los agricultores era deficiente así que antes de la promulgación de las referidas leyes había poco incentivo para la producción agrícola tradicional. iv

Al proceso de inflación se unía en 1943 el de la escasez de los productos de consumo básicov dando como resultado que

...las cantidades de personas que acuden diariamiente a clinicas y dispensarios con afeciones y dolencias que es evidente, tienen su origen en la merma de la calidad y cantidad de los alimentos de mayor consumo popular. Casi todas las dependencias de asistencia social están ahora recargadas a su máximo. (Rodríguez Vega, 1982, p.172).

Tomando en cuenta esto y todo lo anteriormente dicho no es de extrañar que bajo los gobiernos intervencionistas de Calderón Guardia y posteriormente de Picado Michalsky, se promulgara toda una legislación tendiente no solamente a fijar los precios (en contra de las tendencias inflacionistas de la economía) y a fomentar la producción de una agricultura en franca depresión para salvaguardar

\section{(C) $(\Theta \odot \odot$}

La Revista Estudios es editada por la Universidad de Costa Rica y se distribuye bajo una Licencia Creative Commons Atribución-NoComercial-CompartirIgual 3.0 Costa Rica. Para más información envíe un mensaje a 


\section{Especial: Profesores de Estudios Generales Investigan}

la salud de los costarricenses. El Consejo Nacional de Producción, es así, y aunque suene un poco mal, hijo de la guerra.

\section{La Revolución del 48 y la Segunda República. Consejo Nacional de Producción.}

Los años cuarentas presencian el nacimiento de nuevos sectores sociales, una clase media urbana cuyos intereses económicos no concordaban con el del antiguo sector agroexportador. Este nuevo grupo "pretendía desarrollar un proyecto de industrialización y, en general, de diversificación económica." (Murillo, 1986).

La guerra mundial había en efecto demostrado lo vulnerable que puede ser una economía que cifra sus esperanzas en un monocultivo, en nuestro caso era el café. Este grupo, a muchos de cuyos representantes se podían ubicar en el llamado "Centro para los Estudios Nacionales" aspiraba entonces a un Estado intervencionista y desarrollista en franca oposición al liberalismo clásico.

Tras el fraude en la campaña electoral de 1948 este grupo trata de tomar mayor participación el aparato estatal, aliándose a su vez con algunos miembros de sectores cafetaleros que adversaban las reformas sociales y que adversaban también la alianza del partido comunista, al calderonismo (que incluía también algunos sectores cafetaleros) y la iglesia católica.

La revolución encabezada por José Figueres triunfó llevando a cabo un verdadero cambio en el marco institucional con la promulgación de leyes y finalmente (1949) con la una nueva Constitución que es la que aún se encuentra en vigencia.

El Consejo Nacional de Producción no iba a escapar a esta ola de cambios y es ampliamente reestructurado por la Junta Fundadora de la Segunda República (gobierno de transición). Así es como el 20 de mayo de 1948 adscribe el Consejo

\section{(๑) $\Theta \odot$}

La Revista Estudios es editada por la Universidad de Costa Rica y se distribuye bajo una Licencia Creative Commons Atribución-NoComercial-CompartirIgual 3.0 Costa Rica. Para más información envíe un mensaje a 


\section{Especial: Profesores de Estudios Generales Investigan}

al Ministerio de Economía, La Gaceta. 20 de Mayo de 1948. Decreto-Ley N.24) el cual es el encargado de regular y coordinar sus actividades. Seis días después el Consejo se ve ampliado con la representación del Ministro de Economía (La Gaceta 26 de Mayo de 1948. Decreto Ley N.34) el cual es el encargado de regular y coordinar sus actividades. Es entonces que por fin el 10 de Septiembre de 1948 se promulga la Ley N.160 que crea el Consejo Nacional de Crédito y Producción dando muerte técnicamente hablando al antiguo Consejo Nacional de Producción en su artículo primero al derogar todas las leyes relativas al Consejo Nacional de Producción y a la Sección de Fomento de la Producción Agrícola del Banco Nacional de Costa Rica. (La Gaceta. 10 de Septiembre de 1948. Ley N.160). En realidad lo que hace es crear un organismo de mayor autonomía. ${ }^{\text {vi }}$

El Consejo queda integrado así por cuatro miembros: el Ministro de Economía, el de Agricultura, el de Trabajo y el Presidente de la Junta Directiva del

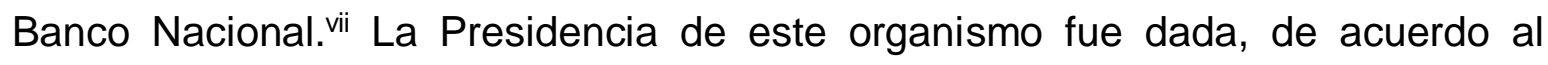
artículo 4 de la Ley, al ministro de Economía. viii

Las atribuciones dadas a este Consejo eran de distinta índole, algunas de ellas heredadas de hecho (no de derecho) de su predecesor. Es importante recalcar que además de labores agrícolas, se señala la industrial, de gran importancia para los anhelos de autosuficiencia económica de este nuevo grupo de poder que tiene las riendas del país en ese momento. Así el artículo séptimo dice textualmente que el Consejo debe "coordinar las actividades de los ministerios representados en él y de los Bancos del Estado, encaminadas a intensificar y perfeccionar la producción agrícola e industrial de:

1. Artículos básicos de consumo popular,

2. Materias primas para las industrias nacionales, y

3. Aquellos otros artículos que a su juicio requieran mejoramiento técnico en su producción y apoyo financiero especial, con miras al desarrollo 


\section{Especial: Profesores de Estudios Generales Investigan}

armónico de la economía nacional." (La Gaceta. 10 de Septiembre de 1948. Ley N.160. Artículo 7).

El desarrollo armónico significa aquí para los redactores de la Ley, en nuestra opinión, exactamente lo contrario a la economía únicamente de carácter agrícola o mono exportadora. Obsérvese que aquí el Consejo Nacional de Crédito y Producción surge como un eficaz instrumento para el fortalecimiento de los nuevos grupos productivos y sus proyectos de desarrollo nacional.

Esta ley confiere al Consejo las funciones de almacenaje "para sostener los precios a nivel de conveniencia para el consumidor y el productor," (La Gaceta. 10 de Septiembre de 1948. Ley N.160. Artículo 7) y para la fijación de precios mínimos "a fin de garantizar las utilidades necesarias para la estabilidad de los agricultores e industriales" (La Gaceta. 10 de Septiembre de 1948. Ley N.160. Artículo 7) y para el financiamiento de proyectos anuales de los ministerios referidos a la producción o relacionados con problemas con carácter de emergencia. (La Gaceta. 10 de Septiembre de 1948. Ley N.160. Artículo 7).

Es interesante observar que se le dan (por medio de los artículos octavo y noveno) dos brazos para su labor. Por un lado el Ministerio de Agricultura, encargado de ejecutar los planes referentes al aumento de la producción, y el Ministerio de Economía, ejecutor de las disposiciones del Consejo que atañen a los procesos de compra, producción y distribución de productos, por cuanto están íntimamente ligados a la regulación de precios, se les dan así mismo los medios materiales (que estén bajo control directo del Banco Nacional o del mismo Consejo).

Los fondos del Consejo provendrán del fondo acumulativo proveniente de la Ley de Abastos N.37 de 1943 con sus modificaciones, o demás fondos que por ley se acordase.

\section{(ब) $\odot \Theta \odot$}

La Revista Estudios es editada por la Universidad de Costa Rica y se distribuye bajo una Licencia Creative Commons Atribución-NoComercial-CompartirIgual 3.0 Costa Rica. Para más información envíe un mensaje a revistaestudios.eeg@ucr.ac.cr. 
Especial: Profesores de Estudios Generales Investigan

El siete de diciembre de 1948 vuelve dar a luz -con ese nombre- al Consejo Nacional de Producción, ya que el nombre de Consejo Nacional de Crédito y Producción "no responde exactamente a las funciones que desempeña, ya que las funciones crediticias no se hallan dentro de las esferas de sus actividades." (La Gaceta, 7 de Diciembre de 1948. Decreto-Ley N.160).

Este fue el inicio de una entidad cuyos objetivos económicos, acordes con el curso de aquellos tiempos, se sintetizaban en el mote de su primer escudo: "Producción nacional es independencia económica."

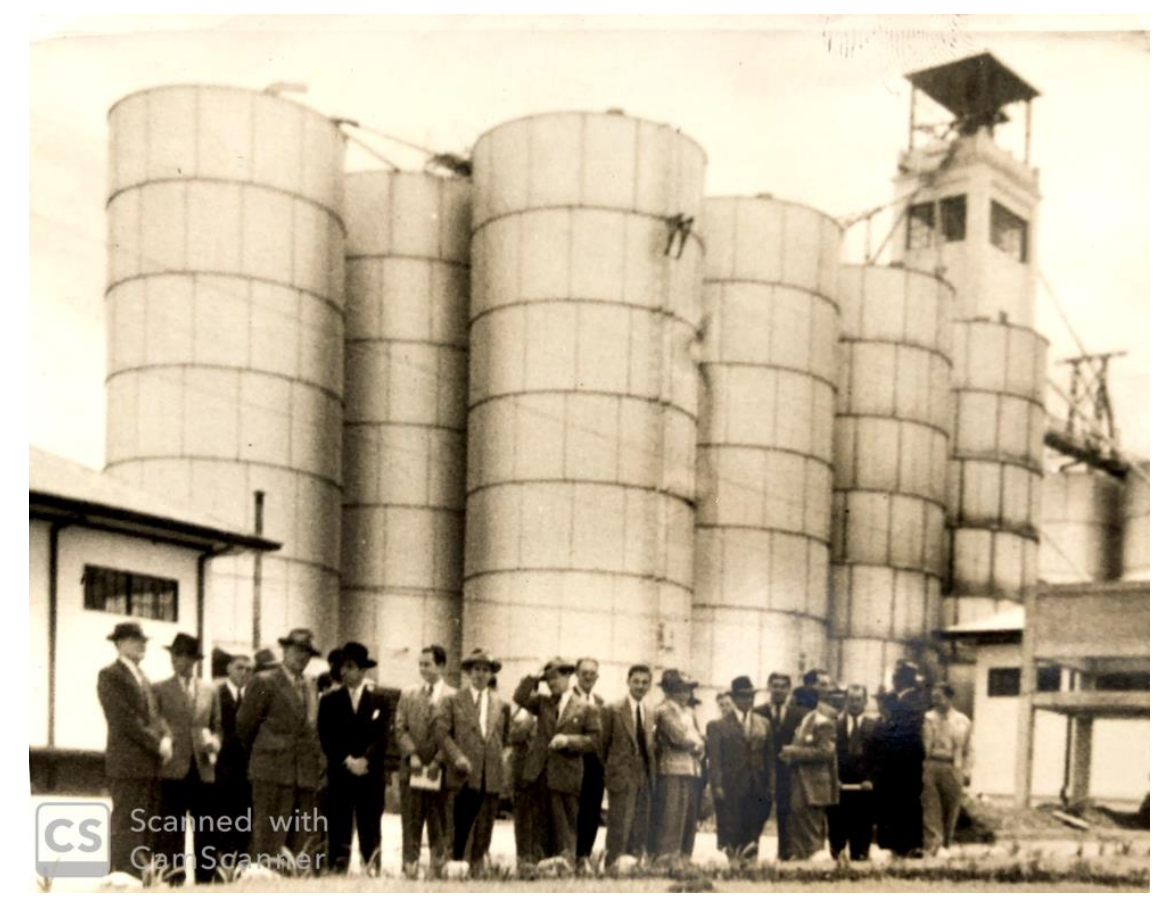

Foto 1. El Consejo Nacional de Producción en sus inicios. Atrás los famosos silos para el almacenamiento de grano. Años 50.

Fuente: Archivo del Consejo Nacional de Producción.

\section{(-) (1)}

La Revista Estudios es editada por la Universidad de Costa Rica y se distribuye bajo una Licencia Creative Commons Atribución-NoComercial-CompartirIgual 3.0 Costa Rica. Para más información envíe un mensaje a revistaestudios.eeg@ucr.ac.cr. 


\section{Los años 50}

\section{Especial: Profesores de Estudios Generales Investigan}

Para el año de 1949 el Consejo de dividía en los departamentos de Economía, de Compras y Distribución y Harinera Nacional, de Fomento Agrícola y en el de la Fábrica Nacional de Licores. Sus programas de trabajo estaban basados en la regulación de precios y artículos de consumo popular y en el fomento de la producción agrícola del país.

Se observa que para estas fechas debió importarse arroz en grandes partidas no "faltando en ningún momento en plaza este importante producto." (Consejo Nacional de Producción, 1950, p.9).

Otros artículos importados fueron el trigo, elementos químicos para los agricultores (240 galones de herbicidas), abonos, motores eléctricos para el molino de trigo de la Sección Industrial Harinera, sedas suizas para cernir harina (de la casa "Kurt Wulff' de Guatemala), maquinaria para refrigeración, esta con un costo de 43.900 colones (de la casa Frick Co.) Además de esto se aceptan las licitaciones de la casa "Willys over land Export Co." de los EE.UU. para el suministro de 8 "jeeps", de la casa "Land Rover" del Reino Unido para un "jeep" y de la casa "Eric.C.Murray Ez Co." para un camión marca "White". Adjudica también cuotas de importación de ganados (200 cabezas cada uno) a distintos ganaderos. (Consejo Nacional de Producción, 1950, p.14).

En el campo de las exportaciones destacamos distintos envíos de frijoles negros principalmente a Venezuela, a Panamá, al Líbano (para la UNICEF) y a Guatemala; Panamá y El Salvador, de maíz a este último país y de miel de abeja a Austria.

\section{(c) (1)(2)}

La Revista Estudios es editada por la Universidad de Costa Rica y se distribuye bajo una Licencia Creative Commons Atribución-NoComercial-CompartirIgual 3.0 Costa Rica. Para más información envíe un mensaje a revistaestudios.eeg@ucr.ac.cr. 


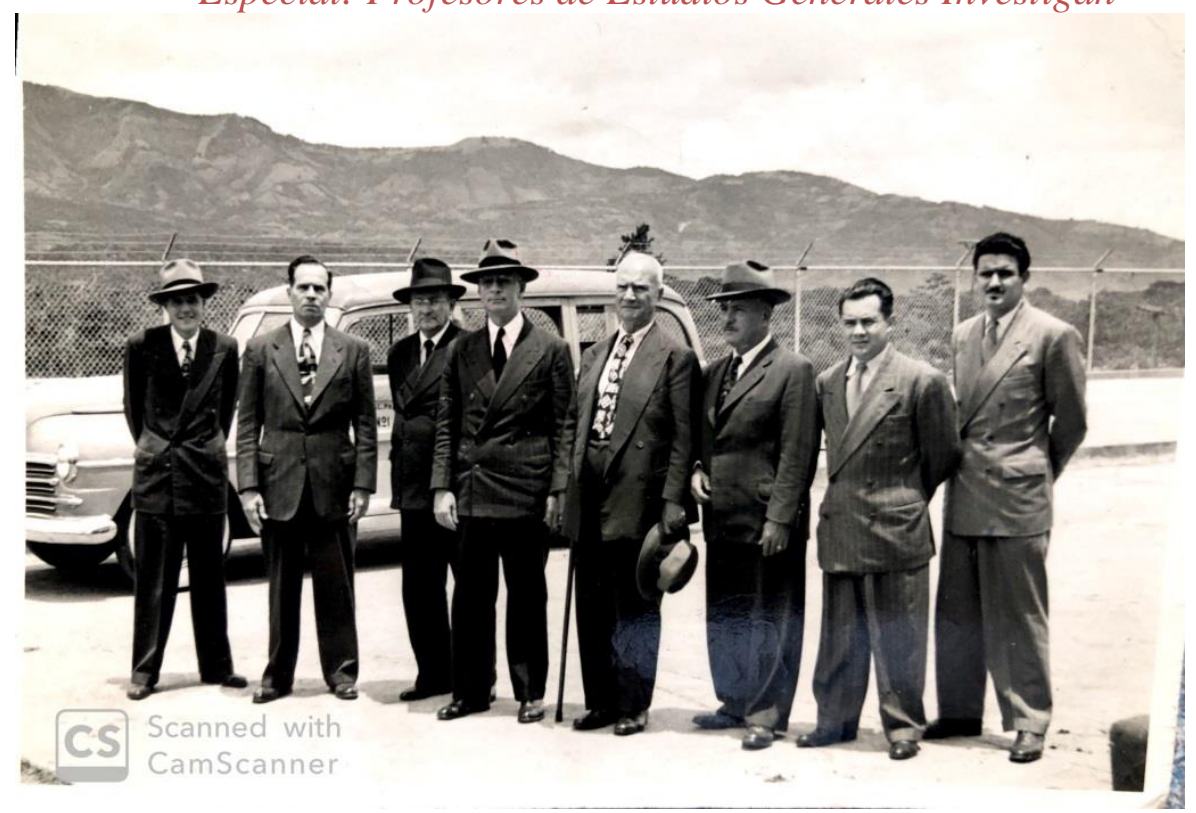

Foto 2. El Consejo Nacional de Producción en sus inicios. Años 50. De izquierda a derecha Ernesto Lara, Carlos Iglesias, Alfredo Hernández Volio, Rufino Gil.

Fuente: Archivo del Consejo Nacional de Producción.

Para el año de 1951 las políticas de intensificación de la producción habían sido altamente efectivas al abastecer el mercado nacional con la producción de 40.000 quintales. Se exporta también (de acuerdo a la cuota asignada por la UNICEF) a Costa Rica 10.000 colones de frijoles a El Salvador (2.200 colones más que para 1949).

La importaciones son diversas como las famosas cámaras frigoríficas, un "Jeep" Willis, manteca, trigo (para la Harinera Nacional), fungicidas y herbicidas, escopetas N.12 y municiones para ellas, estas con el objeto de poder ser usadas por los agricultores para acabar o ahuyentar animales que ponían en peligro sus cosechas. (Producción Nacional (1952), pp.56-58).

Para el período de 1953-4 no se registró ningún excedente en la producción de granos comprados o vendidos por el Consejo, sin embargo se realizaron exportaciones de 40.142 quintales de frijoles con destino a El Salvador y al

\section{(@) $\odot \otimes \odot$}

La Revista Estudios es editada por la Universidad de Costa Rica y se distribuye bajo una Licencia Creative Commons Atribución-NoComercial-CompartirIgual 3.0 Costa Rica. Para más información envíe un mensaje a revistaestudios.eeg@ucr.ac.cr. 
Especial: Profesores de Estudios Generales Investigan

Líbano. Se registraron exportaciones de ganado vacuno (597 cabezas) a Aruba y Curazao (pertenecientes al Reino de los Países Bajos). Se exporta en 1953 arroz a Japón, ajonjolí a Israel, EE.UU. y Cuba. (Producción Nacional, 1954, pp.19-20.)

Las importaciones llevadas a cabo fueron de materiales para la Fábrica Nacional de Licores, concentrados para la Sub-Sección Avícola y trigo para la Harinera. Como importante dato se adquirió equipo para completar la instalación de Los Silos de la Planta de Barranca, ${ }^{i x}$ de enorme capacidad de almacenaje, así como se abrieron a uso del público las plantas frigoríficas, esto en 1955. (Producción Nacional, 1954, pp. 21-23).

Para el año de 1953 se registra un aumento del número de departamentos. El Departamento de Contabilidad hace su aparición en tanto que el de Compra y Distribución pasa a llamarse, en la segunda parte de este año, Departamento de Estabilización.

Las funciones del CNP eran expuestas en 1952 como las de:

...regular los precios de artículos básicos de consumo popular mediante la compra de estos a precios mínimos que garanticen el agricultor justas ganancias como retribución a su trabajo, el almacenamiento y conservación de estos productos para venderlos a los consumidores. (Producción Nacional, 1952, p.4).

Es interesante observar la lógica económica que imperaba detrás de esta concepción. Así se dice que entre mayor capacidad de compra que hubiese en el sector agrícola así aumentaría sus compras en el mercado y su producción se incrementaría, lo que produciría un aumento del ingreso nacional (Producción Nacional, 1954, p.11).

De acuerdo con este pensamiento económico hay tres medios para la estabilización del ingreso agrícola:

a. El Seguro agrícola, para librar a los agricultores de la perdidas totales o parciales de su producción.

\section{(c) (i) (2)}

La Revista Estudios es editada por la Universidad de Costa Rica y se distribuye bajo una Licencia Creative Commons Atribución-NoComercial-CompartirIgual 3.0 Costa Rica. Para más información envíe un mensaje a 
ISSN 1659-3316

\section{Especial: Profesores de Estudios Generales Investigan}

b. El Crédito Agrícola.

c. La fijación de los precios de compra según los costos del producto marginal necesario.

d. Mejoramiento de las vías de comunicación.

Este último punto nos causó gran impresión, ya que el tema ha tenido gran discusión en los últimos tiempos. Citamos entonces el interesante párrafo en toda su extensión.

Las formas rudimentarias de transporte, que en cieras ocasiones pueden ser usadas, exponen a una pérdida segura para el agricultor. Esa pérdida por lo general es el resultado de la imposibilidad de conservar adecuadamente los productos durante el trayecto desde su predio hasta el mercado. Por las razones expuestas anteriormente el Consejo estima conveniente el mejoramiento de las vías de comunicación entre las zonas productoras y los mercados o centros de consumo de los productos agrícolas, para evitar las pérdidas de riqueza que esta ausencia ocasiona, por un lado, y para elevar su ingreso agrícola por otro. (Producción Nacional,1954, p.14).

\section{(C) $(00$}

La Revista Estudios es editada por la Universidad de Costa Rica y se distribuye bajo una Licencia Creative Commons Atribución-NoComercial-CompartirIgual 3.0 Costa Rica. Para más información envíe un mensaje a 
Especial: Profesores de Estudios Generales Investigan

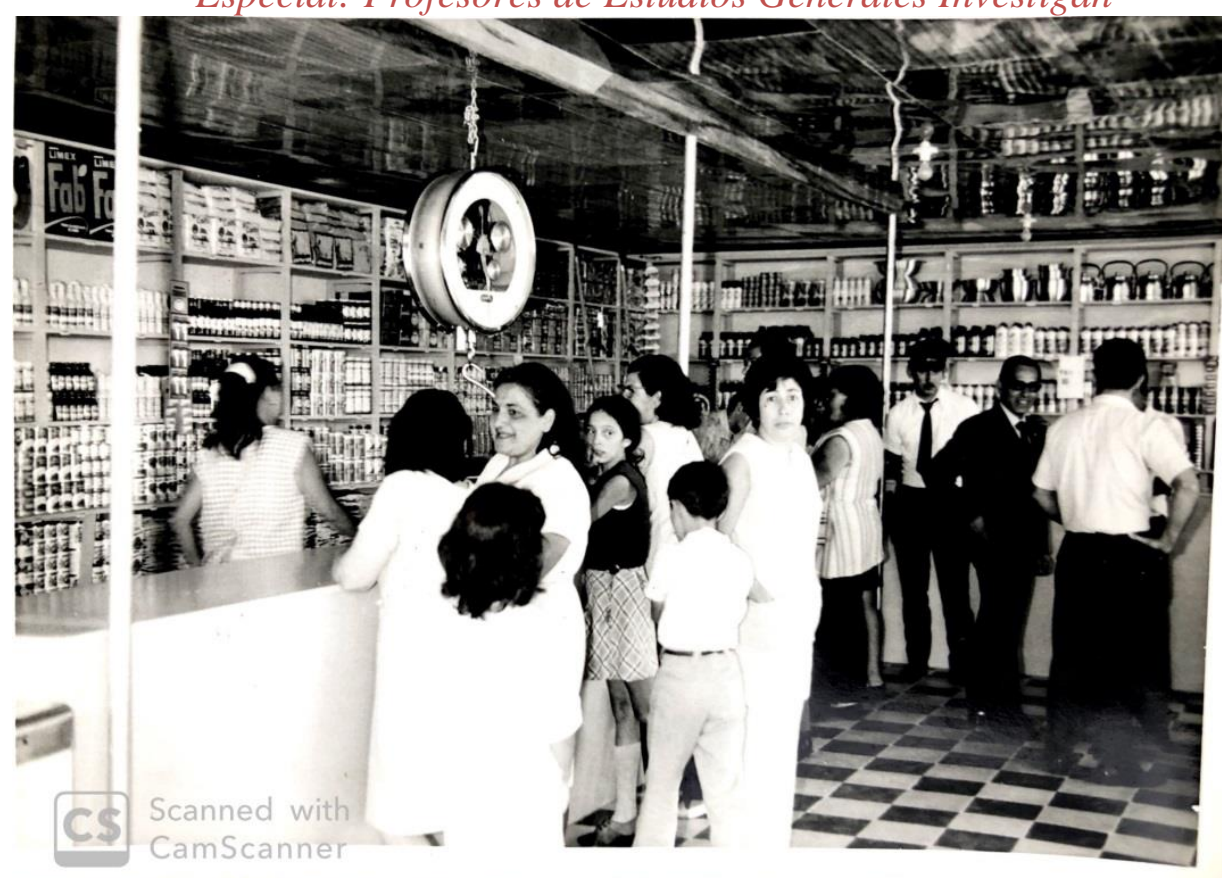

Foto 3. Uno de los expendios del Consejo Nacional de Producción. Fuente: Archivo del Consejo Nacional de Producción.

La estabilización de precios sería lograda por dos medios, los directos; con el control de mecanismos de distribución para ser "capaz de controlar los movimientos de precios nocivos para el país" (Producción Nacional,1954, p.15), esto por medio de los estancos que establecían la competencia directa entre la institución estabilizadora y el comercio privado, y los indirectos, por medio del abastecimiento a los comerciantes mayoristas y minoristas.

En 1956 se le otorga al Consejo Nacional de Producción la autonomía. Estas instituciones tenían el respaldo jurídico del Artículo N.188 de la Constitución Política de 1949 que dice: "Las instituciones autónomas del Estado gozan de independencia en materia de gobierno y administración, y sus directores responden por su gestión." Constitución Política de 1949, citada por (Aguilar, 1979, p.166).

\section{(c) (1) (2) (2)}

La Revista Estudios es editada por la Universidad de Costa Rica y se distribuye bajo una Licencia Creative Commons Atribución-NoComercial-CompartirIgual 3.0 Costa Rica. Para más información envíe un mensaje a revistaestudios.eeg@ucr.ac.cr. 
Facio,

...lo que el régimen autónomo pretende es bien claro; permitir la ampliación administrativa y técnica del Estado en una época cuyos problemas requieren su creciente participación en la vida económica y social, pero evitando al mismo tiempo, que tal aplicación se traduzca en un peligroso acrecentamiento de la autoridad política del Estado y en una deficiente acumulación de nuevas funciones en manos del Poder Ejecutivo. Pareciera ser ésta, la lógica respuesta institucional del Estado, democrático ante la demanda perentoria, por parte de la comunidad y la técnica, de nuevos y complejos servicios públicos... (Facio, 1959, p.54, citado por Aguilar, 1979, p.167).

Es precisamente luego de la administración de Otilio Ulate Blanco (de antiguo cuño liberal) y al indicio de José Figueres Ferrer, del grupo reformista, qe se da inicio a la fundación de instituciones autónomas. Así se autonomiza el Ferrocarril al Pacífico (1954), el Instituto Nacional de Vivienda o Urbanismo INVU en el mismo año, y el Instituto Costarricense de Turismo o ICT. El Consejo Nacional de Producción no escaparía a esa corriente, es así como en el primer y segundo artículo de la Ley Orgánica del Consejo Nacional de Producción de 1956 se nos dice que:

Artículo 1. Créase un Instituto Autónomo del Estado denominado "Consejo Nacional de Producción", que tendrá personería jurídica propia y gozará de la autonomía funcional y administrativa consagrada en el artículo 188 de la Constitución Política. Las decisiones sobre los asuntos que sean de su competencia sólo podrán emanar de la Junta Directiva. (Asamblea Legislativa de la República de Costa Rica,1956, p.3).

Artículo 2. En virtud de lo establecido en el artículo anterior el Consejo tendrá responsabilidad propia en la ejecución de sus funciones, lo cual impone a los miembros de la Junta Directiva la obligación de actuar en la dirección y administración de la Institución, dentro de las disposiciones de las leyes y reglamentos respectivos y de los principios de la técnica y responder por su gestión en forma total e ineludible. (Asamblea Legislativa de la República de Costa Rica,1956, p.3)

\section{(ㄷ) $(\otimes \odot$}

La Revista Estudios es editada por la Universidad de Costa Rica y se distribuye bajo una Licencia Creative Commons Atribución-NoComercial-CompartirIgual 3.0 Costa Rica. Para más información envíe un mensaje a 
Especial: Profesores de Estudios Generales Investigan

La finalidad del Consejo que establece la Ley Orgánica no se diferencia grandemente de la dada por el Decreto Ley N.160 de 1948, se enfatizan, no obstante, las funciones de bien social. Reproducimos en forma total el artículo correspondiente:

Artículo 3. El Consejo tendrá como finalidad específica el fomento de la producción agrícola e industrial y la estabilización de los precios de los artículos requeridos para la alimentación de los habitantes del país, así como los de las materias primas que requiera la industria nacional, procurando un equilibrio justo en las relaciones entre productores y consumidores, con miras al mejoramiento de las condiciones de vida de los costarricenses. Intervendrá en la regulación del mercado interno de tales productos cuando ello sea necesario para estabilizar precios en beneficio de los productores y de los consumidores. En la consecución de su finalidad específica, el Consejo coordinará actividades y colaborará con todos los organismos de crédito, de extensión agrícola, de asistencia técnica, y de cualquier otra índole, cuyo esfuerzo aunado tienda a lograr el fomento de la producción nacional. (Asamblea Legislativa de la República de Costa Rica,1956, p.3)

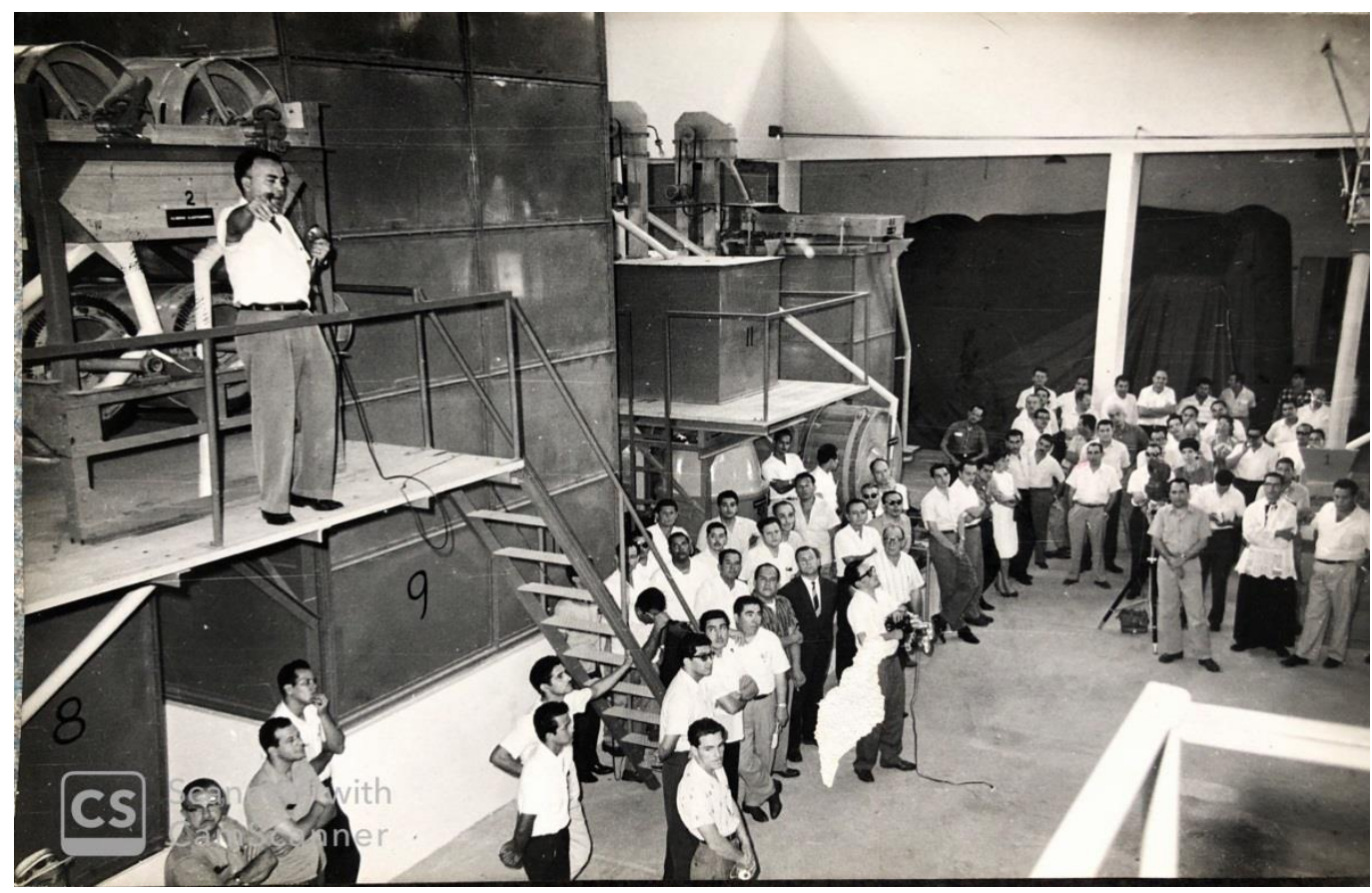

Foto 4. Inauguración de uno de los molinos del Consejo Nacional de Producción. Años 50.

Fuente: Archivo del Consejo Nacional de Producción.

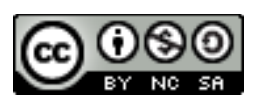

La Revista Estudios es editada por la Universidad de Costa Rica y se distribuye bajo una Licencia Creative Commons Atribución-NoComercial-CompartirIgual 3.0 Costa Rica. Para más información envíe un mensaje a revistaestudios.eeg@ucr.ac.cr. 


\section{Especial: Profesores de Estudios Generales Investigan}

Las funciones específicas son básicamente las mismas, éstas ahora establecidas por el artículo quinto: compra de artículos y fomento de la producción (inciso a), almacenamiento, movilización y transporte de productos agrícolas o pecuarios, compra de semillas, químicos, medicinas y vacunas (inciso b).

Las funciones económicas del Consejo se amplían considerablemente con los incisos siguientes; así el Consejo es habilitado para: comprar animales seleccionados para mejorar la ganadería nacional, adquirir, arrendar y operar maquinarias agrícolas e industriales, para fines agrícolas, así como equipo de pesca", "fomentar la mecanización agrícola". "llevar a cabo trabajos de preparación de suelos que requieran maquinaria pesada, tales como arranque de troncos, hechura de canales y de terrazas", "impulsar y fomentar la actividad privada hacia la industrialización agrícola, pecuaria y pesquera," estimular la formación y el funcionamiento de cooperativas de mercadeo, producción y mecanización en actividades agrícolas y pecuarias, así como las de consumo", dar garantía fiduciaria a personas físicas o jurídicas ante las Instituciones bancarias del Estado en los casos denominados por esa ley", "coadyuvar con el Ministerio de Agricultura e Industrias en el control de las plagas de la agricultura y la ganadería."

El artículo octavo posibilita al Consejo a fijar precios mínimos de compra también para productos de la leche y sus derivados, dulce, panela y similares. El artículo once exime al Consejo de pagar "toda clase de impuestos, ya sea nacionales o municipales, ordinarios o extraodinarios, presentes o futuros" $\sin$ comprender esta exención las tasas municipales ni el impuesto de venta de licores.

Es de gran importancia el artículo 14 de la presente ley ya que estructura administrativamente esta entidad. Así la Junta Directiva estará constituida por un ministro de Estado (veáse que ya no es necesariamente el de Economía el Presidente del Consejo) y por otras cuatro personas de "reconocida experiencia en actividades agrícolas o económicas y con amplios conocimientos de los problemas

\section{(๑) $\odot \odot$}

La Revista Estudios es editada por la Universidad de Costa Rica y se distribuye bajo una Licencia Creative Commons Atribución-NoComercial-CompartirIgual 3.0 Costa Rica. Para más información envíe un mensaje a revistaestudios.eeg@ucr.ac.cr. 


\section{Especial: Profesores de Estudios Generales Investigan}

relativos a la producción nacional" siendo estos elegidos por el Consejo de Gobierno. Esta junta directiva (Art.15) elige a su Presidente y Vicepresidente los cuales durarán en ejercicio de sus funciones un año, el cual no podrá ser un Ministro de Estado (Art.16); lo que a nuestra manera de ver da en teoría una mayor autonomía a la Institución. Los miembros de ella no "podrán participar en actividades político-electorales, salvo con la emisión de su voto o en las que sean obligatorias por ley" (Art.23). Estipula así mismo esta ley toda una serie de regulaciones tendientes al buen uso de la función pública. ${ }^{x}$

Establece también la Gerencia encargada de ejecutar las disposiciones de la Junta Directiva (Art.29) y la Auditoría. La ley deroga también el Decreto-Ley N.160 de 10 de Septiembre de 1948 y otras adiciones, además de cualquier otra disposición contraria a ella.

Con esta legislación se inaugurará así toda una nueva etapa en la vida del Consejo Nacional de Producción; su existencia como institución autónoma que se prolonga hasta el presente.

\section{Bibliografía y otras fuentes}

Aguilar Bulgarelli, O. (1979). La Constitución de 1949. Antecedentes y Proyecciones. San José.

Araya Pochet, C. (1989). Banco Nacional de Costa Rica. 75 años más cerca de Ústed. San José.

Araya Vargas, VH. (1999). De las Cajas a la Junta: la simiente del CNP y su marco jurídico. Consejo Nacional de Producción. San José.

\section{(c) (i)(2)}

La Revista Estudios es editada por la Universidad de Costa Rica y se distribuye bajo una Licencia Creative Commons Atribución-NoComercial-CompartirIgual 3.0 Costa Rica. Para más información envíe un mensaje a 
Especial: Profesores de Estudios Generales Investigan

Asamblea Legislativa de la República de Costa Rica.(1956). Ley Orgánica del Consejo Nacional de Producción.

Consejo Nacional de Producción. (1951-63) Departamento Legal. File 153.Años 1951 a 1963. Asuntos varios al pagaré N. A74253.

Consejo Nacional de Producción. (1948-1954) Libro de Salarios.

Consejo Nacional de Producción. (1949-1950) Libro de Salarios.

Consejo Nacional de Producción. (1950) Memoria correspondiente al período del 1 de Octubre de 1949 al 30 de Septiembre de 1950. San José.

Consejo Nacional de Producción. (1963) Memoria 1962-1963. San José.

Consejo Nacional de Producción. (1971) Oficina de Divulgación. Memoria Anual 1970-1971.

Consejo Nacional de Producción. (1980) Memoria 1979-1980). San José.

Cortés, A. Estado, Empresas Públicas y Desarrollo en Costa Rica: Una mirada de larga duración (1850-2013). Rescatado de:

https://www.tni.org/files/download/8-cortesramos $0 . p d f$

Democracia Costarricense. (1991) Horizontes del Consejo Nacional de Producción. San José.

\section{(c) (7) (-)}

La Revista Estudios es editada por la Universidad de Costa Rica y se distribuye bajo una Licencia Creative Commons Atribución-NoComercial-CompartirIgual 3.0 Costa Rica. Para más información envíe un mensaje a 
Echandi, Jiménez, M. (1984). Banco Nacional de Costa Rica. San José.

Fernández Madrigal, M. (1977). (Tesis de Licenciatura). Consejo Nacional Producción. Evaluación de sus Políticas en Granos Básicos. Universidad de Costa Rica. San José.

Gamboa C. (1982) León Cortés y su época. San José.

Gamboa, C (1985) Costa Rica en la Segunda Guerra Mundial.

Jiménez Mora, F (1998) El Consejo Nacional de Producción. Manuscrito inédito.

La Gaceta. (26. 7. 1944) Ley N.110.

La Gaceta. (20.5.48) Decreto-Ley N.24.

La Gaceta. (26. 5.48) Decreto-Ley N.34.

La Gaceta. (10.9.48) Ley N.160.

León, J 2012. Historia Económica de Costa Rica en el siglo XX. Tomo II: La economía rural. Universidad de Costa Rica. Recuperado de: http://www.iice.ucr.ac.cr/LIBROS/Economia\%20rural.pdf

León, J Las Politicas Económicas en Costa Rica 1850-1950. Recuperado de: http://www.iice.ucr.ac.cr/PoliticaEconomica1890-1950.pdf

\section{(c) (i)(2)}

La Revista Estudios es editada por la Universidad de Costa Rica y se distribuye bajo una Licencia Creative Commons Atribución-NoComercial-CompartirIgual 3.0 Costa Rica. Para más información envíe un mensaje a revistaestudios.eeg@ucr.ac.cr. 


\section{Especial: Profesores de Estudios Generales Investigan}

Mena Redondo, O Evolución del Estado Costarricense y su agenda complementaria.

Rojas Muñoz, N, et als. (2015). La industrialización alimenticia en Costa rica a finales del siglo XX y principios del XXI: De los estancos a los supermercados. Herencia. Vol.28 (1), 31-46 (2015). Recuperado de:

https://webcache.googleusercontent.com/search?q=cache:XwuDg5yNXTAJ:http s://revistas.ucr.ac.cr/index.php/herencia/article/download/21382/21622+\&cd=7\& $\underline{\mathrm{hl}=\mathrm{es} \& \mathrm{ct}=\mathrm{clnk} \& \mathrm{gl}=\mathrm{cr} \& \mathrm{client}=\text { safari }}$

Obregón Loría, R. (1981) Hechos militares y Políticos de Costa Rica. San José.

Producción Nacional. (1952) N.6. Memoria del Consejo Nacional de Producción. San José.

Producción Nacional. (1953 a.) N.9. Memoria del Consejo Nacional de Producción (1952-1953). San José.

Producción Nacional. (1953) Revista del Consejo Nacional de Producción y Oficina del Café. San José.

Producción Nacional. (1954) N.10. Memoria del Consejo Nacional de Producción (1953-1954). San José.

Producción Nacional. (1955). N.11. Memoria del Consejo Nacional de Producción. San José.

Rodríguez Vega, E. (1982) Biografía de Costa Rica. San José.

La Revista Estudios es editada por la Universidad de Costa Rica y se distribuye bajo una Licencia Creative Commons Atribución-NoComercial-CompartirIgual 3.0 Costa Rica. Para más información envíe un mensaje a revistaestudios.eeg@ucr.ac.cr. 
Especial: Profesores de Estudios Generales Investigan

Weirauch, G (1967) The Consejo Nacional de Producción: operations in agricultural price and production regulation by an autonomous government institution in Costa Rica. Associated Colleges of the Midwest. Chicago.

Víquez, V.J. (1975) El Consejo Nacional de Producción y su Participación en el Fomento de Producción de Granos Básicos. Universidad de Costa Rica. (Tesis de Licenciatura)

Zamora Dobles, J (1983). Compendio legal del Consejo Nacional de Producción. San José.

\section{NOTAS}

i Ciertamente hubo algunos antecedentes importantes del CNP. En 18 de Junio de 1912 el Presidente Ricardo Jiménez Oreamuno funda las Cajas Rurales de Crédito, luego Juntas Rurales de Crédito con el objeto de "facilitar y garantizar las operaciones de crédito concernientes a la industria agrícola. No puede ocuparse de negociones que estén fuera de esta esfera de acción." (Vargas, 1999, p.19). Alfredo González Flores crea por otro lado el Banco Internacional de Costa Rica, futuro Banco Nacional de de Costa Rica, y pone a su disposición dos millones de colones como fondo de emergencia con una incidencia en la recolección de las cosechas y la producción así como prestamos a productores de café que sufrieran perdidas por el precio internacional de tal producto. Crea también los Almacenes Generales de Depósito (con el propósito de conservación y deposito de productos agrícolas). Sin embargo parece que un importante intelectual de este plan fue Manuel Mora Valverde, jefe de acción de Ricardo Jiménez Oreamuno, cuando propone el establecimiento de un "Departamento Técnico encargado de estudiar perennemente la capacidad de producción y de consumo del país" además proponía en el Programa de Gobierno de Ricardo Jiménez que el Estado debía garantizar a los agricultores precios mínimos calculados por este Departamento Técnico. En 1940 Rafael Ángel Calderón Guardia firma la ley número 77 que funda la estadística de producción y que dependía de la Secretaría de Estado en los Despachos de Fomento y Agricultura. (Vargas,1999, pp.19-30).

Señala Fernández Madrigal que en 1936 durante el gobierno de don León Cortés Castro el Dr. Herman Max reorganiza "la existente estructura bancaria para fortalecer la operación de las Juntas Rurales de Crédito, a través de las cuales se canalizaba todo el crédito a los agricultores." En Agosto de 1937 se da la Ley n.82 que da paso a un sistema de regulación de precios con vigencia de dos años. Existía un fondo de 200.000 colones y la regulación de precios era llevada a cabo por el Poder Ejecutivo a través de la Sección de Compras de la Secretaría de Hacienda.(Fernández,1977, p.19).

En 6 de Noviembre de 1943 se dictó la ley N.26 donde se crea "la Sección de Fomento de la Producción Agrícola, adscrita a las Juntas Rurales de Crédito Agrícola del Banco Nacional de Costa Rica, destinada a dar protección y estímulo a la producción de artículos agrícolas de consumo popular, amparando a su vez los intereses de los consumidores." (Viquez 1975, p.3).

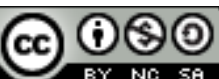

La Revista Estudios es editada por la Universidad de Costa Rica y se distribuye bajo una Licencia Creative Commons Atribución-NoComercial-CompartirIgual 3.0 Costa Rica. Para más información envíe un mensaje a 


\section{Especial: Profesores de Estudios Generales Investigan}

Esta ley garatiza un precio fijo a los agricultores que posibilita un contrato de compra por medio del Banco Nacional de Costa Rica con carácter de promesa obligatoria. Se crea así, apunta Víquez Arguedas, un fondo de 1.500 .000 colones para la compra de arroz, frijoles, papas y maíz. (Víquez 1975, p.3).

Para Weirauch el Consejo Nacional de Producción se crea en 1943 cuando una nueva sección al Departamento de Agricultura del Banco Nacional (Sección de Fomento de Producción)

The Consejo Nacional de Producción got its start in 1943 when a new section was added to the Agriculture Department of the Banco Nacional, which it may be remembered, was the country's first autonomous institution which plays the leading part in agricultural credit activities today. (Weirauch, 1967 p.3).

ii (Gamboa, 1982, p.74). La Secretaría de Agricultura e Industria separada de la Secretaría de Fomento es creada por el gobierno de Cortés, pero en realidad es puesta a funcionar hasta agosto de 1942 por el gobierno de Calderón Guardia. Son creadas también la Junta de Cooperación Agrícola cuyo objetivo era

estudiar e investigar todos los problemas relacionados con la agricultura en estrecho vínculo con la secretaría respectiva; son respaldados los Almacenes Generales de Depósito (que datan de 1917) cuya función era custodiar los productos y mercancías en épocas de bajo precio, se funda la Bolsa de Café, se restablecen las Juntas Rurales de Crédito (1937) y Cortés respalda la diversificación agrícola, en suma todo un precedente a los cambios que habrían de venir (Gamboa, 1982, pp.76-77).

iii Un fenómeno que fue acompañado por la movilización de mano de obra a las plantaciones bananeras del Pacífico Sur tras el contrato bananero de 1938 y a las obras de infraestructura del gobierno y en la carretera interamericana. (Gamboa, 1982, p.75).

iv Los préstamos hechos a la agricultura y a la industria eran menores que los hechos al comercio. Así tenemos los porcentajes de 25,89\% (agricultura) contra 74,11\% (comercio). (Gamboa, 1982, p.75).

${ }^{\vee}$ Esto queda demostrado por los cálculos hechos por Gamboa. Así el monto de los préstamos a la agricultura y a la industria es definitivamente menor que el hecho al comercio. Así tenemos los porcentajes de $25,89 \%$ contra $74,11 \%$, (Gamboa, 1985, p.120).

vi Decimos esto en contraposición al Decreto-Ley N.160 del siete de Diciembre de 1948 que afirma que;

Como organismo autóctono que es el actual Consejo Nacional de Producción podrá celebrar contratos con instituciones u organismos del Estado, personas o entidades particulares y corporaciones o entidades extranjeras, con el fin de llevar a cabo proyectos especiales de fomento o mejoramiento agrícola, ganadero o industrial.

Vemos entonces como el Decreto Ley N.160 en realidad restringiría ese portillo autonómico que le daba mayor personalidad jurídica. (La Gaceta. 10 de Septiembre de 1948. Ley N.160).

vii Lo que hace es reafirmar aquí lo dicho por el Decreto-Ley N. 34 con la novedad que se habla de ministerios de Trabajo y Agricultura y ya no se de secretarías.

viii "o en caso de ausencia temporal del mismo, el miembro de Consejo designado por rotación" (La Gaceta. 10 de Septiembre de 1948. Ley N.160).

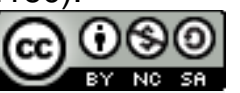

La Revista Estudios es editada por la Universidad de Costa Rica y se distribuye bajo una Licencia Creative Commons Atribución-NoComercial-CompartirIgual 3.0 Costa Rica. Para más información envíe un mensaje a revistaestudios.eeg@ucr.ac.cr. 


\section{Especial: Profesores de Estudios Generales Investigan}

ix Debido a la magnitud de las compras realizadas durante el período -más de 600.000 quintales- a la Institución se le plantearon muy serios problemas de conservación y transporte. A pesar de las dificultades que se les debieron presentar, es importante apuntar que la movilización y almacenamiento de las cosechas se llevó a cabo de manera satisfactoria, el problema se resolverá de manera permanente una vez que se pongan en servicio los silos de Barranca, una de las obras de fines socio-económicos más importantes levantadas en el país con un costo de varios millones de colones. (Producción Nacional, 1954, p.39).

× Por ejemplo ver los artículos 18, 21, 26 y 27.

\section{(c) (i) (2)}

La Revista Estudios es editada por la Universidad de Costa Rica y se distribuye bajo una Licencia Creative Commons Atribución-NoComercial-CompartirIgual 3.0 Costa Rica. Para más información envíe un mensaje a revistaestudios.eeg@ucr.ac.cr. 